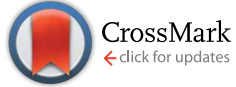

Cite this: J. Mater. Chem. B, 2014, 2 , 7250

Received 6th June 2014

Accepted 10th September 2014

DOI: $10.1039 / c 4 t b 00922 c$

www.rsc.org/MaterialsB

\section{Calcium phosphate increases the encapsulation efficiency of hydrophilic drugs (proteins, nucleic acids) into poly(D,L-lactide-co-glycolide acid) nanoparticles for intracellular delivery}

\author{
Gregor Dördelmann, ${ }^{a}$ Diana Kozlova, ${ }^{a}$ Sarah Karczewski, ${ }^{\text {b }}$ Rosario Lizio, ${ }^{c}$ \\ Shirley Knauer ${ }^{b}$ and Matthias Epple*a
}

\begin{abstract}
Calcium phosphate/poly(D,L-lactide-co-glycolide) (PLGA) nanoparticles with a diameter below $200 \mathrm{~nm}$, loaded with either nucleic acids or proteins, were synthesized by a water-in-oil-in-water $\left(W_{1} / O / W_{2}\right)$ emulsion solvent evaporation technique. The particles were stabilized by polyvinyl alcohol (PVA) and had a negative charge (zeta potential $-26 \mathrm{mV}$ ). By the addition of calcium phosphate into the inner aqueous phase of the $\mathrm{W}_{1} / \mathrm{O} / \mathrm{W}_{2}$-emulsion, the encapsulation efficiency of siRNA was increased to $37 \%$, of DNA to $52 \%$, and of bovine serum albumin to $78 \%$, i.e. by a factor of 3 to 10 compared to PLGA nanoparticles without calcium phosphate. Total loadings of $8 \mu \mathrm{g}$ siRNA, $5 \mu \mathrm{g}$ DNA and $280 \mu \mathrm{g}$ fluorescein isothiocyanate-labelled bovine serum albumin (FITC-BSA) per mg of PLGA nanoparticles were achieved by this method. The addition of an outer layer of either chitosan or polyethyleneimine (PEI) reversed the charge of the particles (zeta potential $>+30 \mathrm{mV}$ ) and improved the cellular uptake as well as the endosomal escape of these particles as demonstrated by confocal laser scanning microscopy. Calcium phosphate-PLGA nanoparticles loaded with DNA encoding for enhanced green fluorescent protein (eGFP-DNA) showed a good transfection efficiency for epithelial cells (HeLa). Gene silencing with HeLa cells expressing eGFP gave knockdown efficiencies of $53 \%$ for anionic nanoparticles, of $68 \%$ for chitosan-coated cationic nanoparticles, and of $89 \%$ for polyethyleneimine-coated cationic nanoparticles.
\end{abstract}

\section{Introduction}

According to the biopharmaceutical classification system, it is a challenge in modern drug delivery to administrate watersoluble, especially negatively charged (bio-)molecules to cells because they are often unable to penetrate the cell membrane on their own and are also sensitive to enzymatic degradation, e.g. by nucleases or proteases. ${ }^{1-3}$ Classical examples for hydrophilic drugs are nucleic acids, i.e. DNA or siRNA, for transfection, gene silencing and gene therapy, and proteins. Typically, carriers like liposomes, viruses or nanoparticles are necessary to transport such biomolecules across the cell membrane..$^{2,4-8}$

Poly(D,L-lactide-co-glycolide) (PLGA) is a biocompatible and biodegradable polymer. ${ }^{9}$ It has been approved by the Food and Drug Administration (FDA) and is frequently used as a polymeric nanoparticulate carrier system for the delivery of

\footnotetext{
anorganic Chemistry and Center for Nanointegration Duisburg-Essen (CeNIDE), University of Duisburg-Essen, Universitaetsstr. 5-7, 45117 Essen, Germany. E-mail: matthias.epple@uni-due.de; Fax: +49 201 1832621; Tel: +49 2011832402

${ }^{b}$ Molecular Biology, Center for Medical Biotechnology (ZMB), University of DuisburgEssen, Universitaetsstr. 545117 Essen, Germany

${ }^{c}$ Evonik Industries AG, Rodenbacher Chaussee 4, 63457 Hanau, Germany
}

biopharmaceuticals. ${ }^{\mathbf{1 0 - 1 3}}$ In addition to its biocompatibility and biodegradability, PLGA possesses excellent controllable release properties. The drug release profile can be tuned by the molecular weight, the block copolymer composition, the size and the morphology of the nanoparticles. ${ }^{14}$ Although previous reports have shown that PLGA nanoparticles are promising carriers for plasmid DNA and siRNA, it is still challenging to encapsulate hydrophilic biomolecules (especially siRNA) into a PLGA matrix by classical emulsion techniques. ${ }^{15-17}$ Because of their high water solubility, nucleic acids and proteins tend to diffuse into the continuous aqueous phase during the emulsion process. Therefore, the encapsulation efficiency for such compounds is typically low. ${ }^{18}$ A well-established method to increase the encapsulation efficiency of nucleic acids into polymeric matrices is to prepare polyplexes of siRNA or DNA with cationic polymers like polyethyleneimine (PEI). Alternatively, the nucleic acid can be inserted into a liposome or lipid nanoparticles, formed by surfactants like 1,2-dioleoyl-3-trimethylammoniumpropane (DOTAP). ${ }^{19,20}$ However, in addition to an altered and retarded release profile, many of these compounds are cytotoxic. ${ }^{21-23}$

In contrast to polyplexes or liposomes, calcium phosphate as the inorganic part of hard tissue like bone, teeth, and tendons is 


\section{A Calcium phosphate-PLGA nanoparticles}

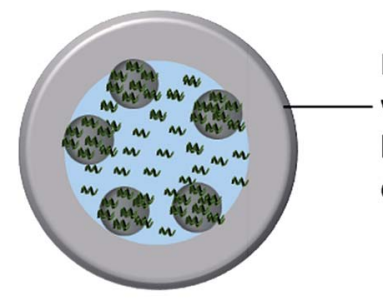

Enhanced loading with biomolecules by the addition of calcium phosphate

\section{B PLGA nanoparticles}

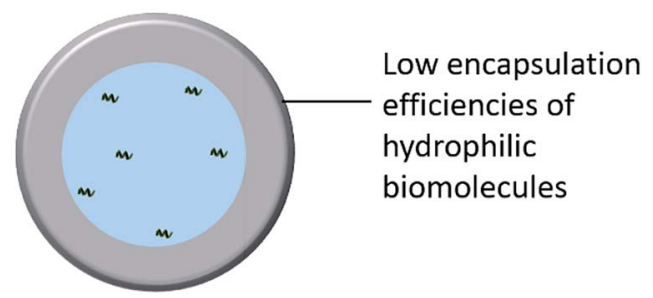

Fig. 1 Schematic illustration of the improved loading efficiency of nucleic acids by the addition of calcium phosphate nanoparticles.

known for its biocompatibility. ${ }^{24,25}$ In addition, calcium phosphate nanoparticles have a high affinity to nucleic acids and proteins and are efficiently taken up by cells and subsequently dissolved in lysosomes at a $\mathrm{pH}$ below $5 .{ }^{26-32}$ Thus, they can be used as carriers for biomolecules ${ }^{7}$ and synthetic molecules ${ }^{8,33-35}$ across the cell membrane.

The aim of this study was to synthesize a drug delivery system based on calcium phosphate and PLGA nanoparticles for sensitive hydrophilic biomolecules like siRNA, DNA, and proteins with increased encapsulation efficiencies compared to classical PLGA nanoparticles (Fig. 1). In addition, the improvement of the storability compared to "single shell" calcium phosphate nanoparticles by the incorporation into a PLGA matrix, followed by freeze-drying, was investigated. ${ }^{36-38}$

\section{Experimental}

\section{Materials}

Poly(D,L-lactide-co-glycolide) $50: 50$ (Resomer® RG 502 H, $\left.M_{\mathrm{w}}=7000-17000 \mathrm{~g} \mathrm{~mol}^{-1}\right)$ was obtained from Evonik Industries (Darmstadt). Polyvinyl alcohol (PVA, $M_{\mathrm{w}}=30000-70000 \mathrm{~g}$ $\mathrm{mol}^{-1}, 87-90 \%$ hydrolysed), chitosan (Aldrich, low molecular weight, $75-85 \%$ deacetylated) and polyethyleneimine (PEI, $M_{\mathrm{w}}=25000 \mathrm{~g} \mathrm{~mol}^{-1}$ ) were purchased from Sigma-Aldrich. For gene silencing experiments with anti-eGFP-siRNA, desalted, double-stranded siRNA from Invitrogen, Ambion ${ }^{\circledR}$ (Carlsbad, USA), sense, 5'-GCAAGCUGACCCUGAAGUUCAU-3' and antisense, $5^{\prime}$-AUGAACUUCAGGGUCAGCUUGC-3' ${ }^{\prime}\left(M_{\mathrm{w}}=14019.5 \mathrm{~g}\right.$ $\mathrm{mol}^{-1}$ ) was used. For transfection experiments with plasmid DNA, pcDNA3-eGFP $\left(M_{\mathrm{w}}=3621600 \mathrm{~g} \mathrm{~mol}^{-1}\right.$, computed from the number of base pairs in the plasmid DNA) encoding for enhanced fluorescent protein (eGFP) was isolated from Escherichia coli using a Nucleobond endotoxin-free plasmid DNA kit
(Macherey-Nagel, Dueren, Germany). All other chemicals were of analytical grade and used without further purification.

\section{Instruments}

For the formation of water-in-oil and water-in-oil-in-water emulsions, ultrasonication was carried out with a Hielscher UP50H instrument, sonotrode MS2, 70\% amplitude, pulse 0.7, for $20 \mathrm{~s}$. Scanning electron microscopy was performed with an ESEM Quanta 400 instrument with gold/palladium-sputtered samples. Dynamic light scattering and zeta potential determinations were performed with a Zetasizer nanoseries instrument (Malvern Nano-ZS, laser: $\lambda=532 \mathrm{~nm}$ ) using the Smoluchowski approximation and taking the data from the Malvern software without further correction. The particle size data refer to scattering intensity distributions ( $z$-average). Confocal laser scanning microscopy was performed with a confocal laser scanning microscope (SP5 LCSM, Leica) using a $63 \times$ water objective. The laser wavelength was $488 \mathrm{~nm}$ for FITC excitation (emission: 500-520 nm) and $561 \mathrm{~nm}$ for RFP excitation (emission: 580-600 $\mathrm{nm})$. Centrifugation was performed at $4{ }^{\circ} \mathrm{C}$ with a Heraeus Fresco 21 instrument (Thermo Scientific). Transfection and gene silencing efficiencies were determined by transmission light and fluorescence spectroscopy with a Carl Zeiss Axiovert 40 CFL instrument. The viability of the cells was analysed by the MTT-Test by spectrophotometric analysis with a Multiscan FC instrument (ThermoFisher scientific, Vantaa, Finland) at $\lambda=$ $570 \mathrm{~nm}$. Freeze-drying was performed with a Christ, Alpha 2-4 LSC instrument. Statistical analysis was carried out using Student's $t$-test.

\section{Synthesis of calcium phosphate nanoparticles, loaded with nucleic acids}

For the synthesis of calcium phosphate nanoparticles carrying either anti-eGFP-siRNA or eGFP-DNA, we modified the rapid precipitation method (Fig. 2A) that we had reported earlier. ${ }^{\mathbf{2 0 , 2 1}}$ Aqueous solutions of calcium nitrate $(6.25 \mathrm{mM}, 105 \mu \mathrm{L})$ and diammonium hydrogen phosphate $(3.74 \mathrm{mM}, 105 \mu \mathrm{L})$ were mixed in a tube reactor with a syringe pump and pumped under continuous mixing (Vortex) either into an aqueous solution of eGFP-DNA $\left(2.5 \mathrm{mg} \mathrm{mL} \mathrm{mL}^{-1}, 40 \mu \mathrm{L}\right)$ or into a solution of anti-eGFPsiRNA $\left(3.9 \mathrm{mg} \mathrm{mL}^{-1}, 40 \mu \mathrm{L}\right)$. The flow rate of both solutions was 16.6 $\mu \mathrm{L} \mathrm{s}^{-1}$, and the residence (nucleation) time in the $\mathrm{Y}$ adapter (7 mm length) was $1.3 \mathrm{~s}$. After the completed precipitation, the dispersion of the nanoparticles (core: calcium phosphate; shell: nucleic acid) was cooled on ice and used after $5 \mathrm{~min}$ of incubation for the encapsulation into PLGA nanoparticles.

\section{Synthesis of nucleic acid-loaded calcium phosphate PLGA nanoparticles}

For the encapsulation of either eGFP-DNA- or siRNA-functionalized calcium phosphate nanoparticles into PLGA nanoparticles, a waterin-oil-in-water $\left(\mathrm{W}_{1} / \mathrm{O} / \mathrm{W}_{2}\right)$ double emulsion solvent evaporation method was applied (Fig. 2B). To a solution of $10 \mathrm{mg}$ PLGA dissolved in $750 \mu \mathrm{L}$ dichloromethane, $250 \mu \mathrm{L}$ of the dispersion of calcium phosphate/nucleic acid nanoparticles was added. Then a solution of 


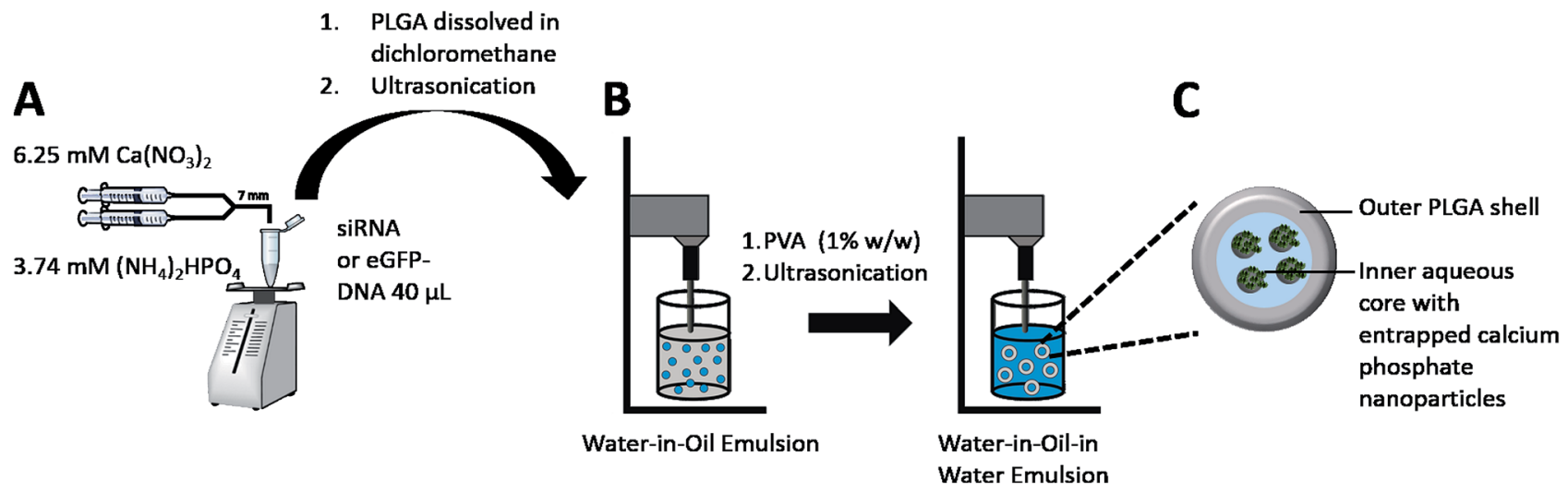

Fig. 2 Synthesis of nucleic acid-loaded calcium phosphate nanoparticles (A) and their encapsulation into a PLGA matrix by the $\mathrm{W}_{1} / \mathrm{O} / \mathrm{W}_{2}-$ emulsion technique (B). Structure and composition of a PLGA particle which carries drug-loaded calcium phosphate nanoparticles (C).

$200 \mu \mathrm{g}$ RNase-free acetylated bovine serum albumin (BSA) in $40 \mu \mathrm{L}$ water as dispersant was added. The mixture was ultrasonicated (sonotrode) to form the primary, milky white $\mathrm{W}_{1} / \mathrm{O}$-emulsion. The $\mathrm{W}_{1} / \mathrm{O}$-emulsion was then immediately poured into the continuous water phase $(3 \mathrm{~mL})$, containing $30 \mathrm{mg}$ polyvinyl alcohol (PVA) as dispersant, and ultrasonicated again (sonotrode). Finally, the PLGA nanoparticles were precipitated after the dichloromethane was removed under reduced pressure (200-600 mbar) in a rotary evaporator. Thereby, the calcium phosphate nanoparticles carrying siRNA or DNA were incorporated into a nanoparticulate matrix of PLGA. The excess of PVA was removed by centrifugation ( $30 \mathrm{~min}$ at $14800 \mathrm{rpm}$ ), and redispersion of the particles in ultrapure water, repeated three times each. The resulting dispersion was shockfrozen in liquid nitrogen and finally lyophilized for $72 \mathrm{~h}$ at $0.31 \mathrm{mbar}$ and $-10^{\circ} \mathrm{C}$. The particles were easily redispersible in water by gentle shaking.

The encapsulation efficiency (EE) of the nucleic acids was calculated by eqn (1). The content of nucleic acids in the supernatant was analysed by UV/Vis spectroscopy at $260 \mathrm{~nm}$ according to standard protocols after separation of the nanoparticles by centrifugation.

$$
\mathrm{EE}(\%)=\frac{\mathrm{BM}(\mathrm{i})-\mathrm{BM}(\mathrm{s})}{\mathrm{BM}(\mathrm{i})} \times 100 \%
$$

EE (\%): encapsulation efficiency in percent; BM(i): total amount of biomolecule added initially; $\mathrm{BM}(\mathrm{s})$ : amount of biomolecule in the supernatant measured by quantitative UV/Vis spectroscopy.

\section{Synthesis of protein-loaded calcium phosphate-PLGA nanoparticles}

Calcium phosphate-FITC-BSA-PLGA nanoparticles were synthesised by a $\mathrm{W}_{1} / \mathrm{O} / \mathrm{W}_{2}$ emulsion solvent evaporation method (Fig. 3), by modification of a synthesis reported by Tang et al. ${ }^{39}$ First, two W/O emulsions (A and B) were prepared by ultrasonication. For emulsion A, $625 \mu \mathrm{g}$ FITC-BSA was dissolved in $125 \mu \mathrm{L}$ of a $10 \mathrm{mM}$ solution of $\mathrm{Na}_{2} \mathrm{HPO}_{4}$. This was dispersed in a solution of PLGA in dichloromethane $\left(13.3 \mathrm{mg} \mathrm{mL}^{-1}, 375 \mu \mathrm{L}\right)$.

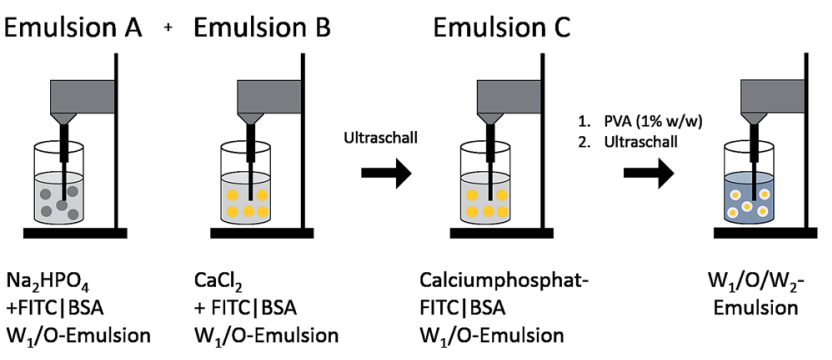

Fig. 3 Schematic pathway of the synthesis of PLGA nanoparticles, loaded with calcium phosphate nanoparticles that carried FITClabelled BSA (FITC-BSA).

For emulsion B, $625 \mu \mathrm{g}$ FITC-BSA was dissolved in $125 \mu \mathrm{L}$ of a 1.25 M solution of $\mathrm{CaCl}_{2}$. This was dispersed in a solution of PLGA in dichloromethane $\left(13.3 \mathrm{mg} \mathrm{mL} \mathrm{m}^{-1}, 375 \mu \mathrm{L}\right)$. Then, emulsions $\mathrm{A}$ and $\mathrm{B}$ were mixed by ultrasonication to form emulsion $\mathrm{C}$. This $\mathrm{W}_{1} / \mathrm{O}$-emulsion was then added dropwise to the continuous water phase $(3 \mathrm{~mL})$, containing $30 \mathrm{mg}$ PVA as dispersant, and ultrasonicated again (sonotrode) to form a yellow, milky $\mathrm{W}_{1} / \mathrm{O} / \mathrm{W}_{2}$-emulsion. After removal of dichloromethane under reduced pressure (200-600 mbar), the calcium phosphate-FITC-BSA nanoparticles were incorporated into the PLGA particle. Any excess of PVA and FITC-BSA was removed by centrifugation ( $30 \mathrm{~min}$ at $14800 \mathrm{rpm}$ ), and redispersion of the particles in ultrapure water by ultrasonication (sonotrode), repeated three times. The resulting dispersion was shock-frozen in liquid nitrogen and finally lyophilised for $72 \mathrm{~h}$ at $0.31 \mathrm{mbar}$ and $-10{ }^{\circ} \mathrm{C}$. The particles were easily redispersible in water by gentle shaking.

The encapsulation efficiency (EE) of FITC-BSA was calculated by eqn (1) as described above. The supernatants were analysed by UV/Vis spectroscopy at $460 \mathrm{~nm}$ after previous calibration with dissolved FITC-BSA.

\section{Charge reversal of anionic PLGA nanoparticles by coating with either PEI or chitosan}

To enhance the cellular uptake and the endosomal escape, the surface of the negatively charged PLGA nanoparticles was 
coated with a cationic polyelectrolyte, i.e. either PEI or chitosan. $1.5 \mathrm{mg}$ of the freeze-dried particles were resuspended in $1 \mathrm{~mL}$ ultrapure water and added dropwise to either an aqueous PEI solution $(2 \mathrm{mg}$ in $1 \mathrm{~mL})$ or an aqueous chitosan solution $(5 \mathrm{mg}$ in $1 \mathrm{~mL}, \mathrm{pH}$ adjusted to 5 with acetic acid) under continuous stirring. After 30 min of continuous stirring at room temperature, the dispersion was purified three times by centrifugation (30 min at $14800 \mathrm{rpm}$ ), and redispersion (shaking, no ultrasonication necessary) in ultrapure water. For cell culture experiments, the particles were finally redispersed in the cell culture medium used.

\section{Cell culture experiments}

HeLa and HeLa-eGFP cells (genetically modified HeLa cells that express enhanced green fluorescent protein, eGFP) were cultivated in Dulbecco's modified Eagle's medium (DMEM) supplemented with $10 \%$ fetal calf serum (FCS), $100 \mathrm{U} \mathrm{mL}^{-1}$ penicillin, and $100 \mathrm{U} \mathrm{mL}^{-1}$ streptomycin at $37{ }^{\circ} \mathrm{C}$ under $5 \% \mathrm{CO}_{2}$ atmosphere. $12 \mathrm{~h}$ before the addition of the nanoparticles, the cells were trypsinized and seeded in 24-well plates with a density of either $2.5 \times 10^{4}$ cells per well (for transfection and gene silencing experiments) or $10^{5}$ cells per well (for uptake studies).

The cell viability was analysed by the MTT-assay $72 \mathrm{~h}$ after the transfection. MTT (3-(4,5-dimethylthiazol-2-yl)-2,5diphenyltetrazolium bromide; Sigma, Taufkirchen, Germany) was dissolved in PBS $\left(5 \mathrm{mg} \mathrm{mL}{ }^{-1}\right)$ and then added to the required cell culture medium, giving a final MTT concentration of $1 \mathrm{mg} \mathrm{mL}{ }^{-1}$. The cell culture medium of transfected cells was replaced by the MTT medium $(300 \mu \mathrm{L})$ and incubated for $90 \mathrm{~min}$ at $37{ }^{\circ} \mathrm{C}$ under $5 \% \mathrm{CO}_{2}$ in humidified atmosphere. Then, the MTT medium was removed and the blue precipitate was dissolved in DMSO ( $300 \mu \mathrm{L}$, each well) and incubated for $30 \mathrm{~min}$. Finally, $100 \mu \mathrm{L}$ of each well were taken for spectroscopic analysis at $\lambda=570 \mathrm{~nm}$. The absorption of cells treated with nanoparticles was normalized to that of the control (untreated cells).

\section{Cell uptake studies}

For co-localization experiments, HeLa cells were seeded in 8well plates (Lab-Tek) and cultivated for $24 \mathrm{~h}$. Then, HeLa cells were transfected with $50 \mathrm{ng}$ of lysosomal-associated membrane protein 1 (Lamp1)-RFP plasmid-DNA and $0.3 \mu \mathrm{L}$ Lipofectamine 2000 (Life technologies) according to the manufacturer's instructions. After $4 \mathrm{~h}$, the cell culture medium was changed, and the cells were washed for several times with PBS. After additional $16 \mathrm{~h}$, cells were treated with the nanoparticle dispersion $(20 \mu \mathrm{L}, 1 \mathrm{mg}$ nanoparticles per $\mathrm{mL})$ and examined with a confocal laser scanning microscope at different time points as described earlier. ${ }^{40}$

\section{Transfection of HeLa cells with either anti-eGFP-siRNA or eGFP-DNA functionalized calcium phosphate-PLGA nanoparticles}

The transfection was carried out according to our protocols reported earlier. ${ }^{30,36,41}$ Before the transfection, the cell culture medium was replaced by the nanoparticles redispersed in fresh cell culture medium $(0.1 \mathrm{mg}$ nanoparticles in $0.5 \mathrm{~mL}$ corresponding to $0.29 \mu \mathrm{g}$ DNA or $0.8 \mu \mathrm{g}$ siRNA per well). After incubation for $7 \mathrm{~h}$, the transfection medium was replaced by fresh cell culture medium. As control, the cells were transfected with Lipofectamine 2000 as recommended by the manufacturer. In brief, $50 \mu \mathrm{L}$ of FCS-free DMEM were mixed with $1 \mu \mathrm{L}$ Lipofectamine 2000 and incubated for $5 \mathrm{~min}$ at room temperature. Either eGFP-siRNA ( $20 \mathrm{pmol}, 0.28 \mu \mathrm{g})$ or eGFP-DNA $(1 \mu \mathrm{g})$ were added to $50 \mu \mathrm{L}$ of FCS-free DMEM. Then, both solutions were mixed and incubated for $20 \mathrm{~min}$ before $100 \mu \mathrm{L}$ of this solution and additionally $400 \mu \mathrm{L}$ of DMEM were added to each well. After incubation for $7 \mathrm{~h}$, the transfection medium was replaced by fresh cell culture medium. The transfection efficiency and the efficiency of the gene silencing were measured $72 \mathrm{~h}$ after the addition of the nanoparticles by light and fluorescence microscopy.

The transfection efficiency of the experiments with eGFPDNA-functionalized calcium phosphate-PLGA nanoparticles was calculated by the ratio of green fluorescing cells to the total number of cells. The efficiency of the gene silencing experiments with eGFP-siRNA-functionalized calcium phosphatePLGA nanoparticles was calculated as reported earlier: ${ }^{38}$

$$
\text { GE }(\%)=\frac{\text { silenced cells }(\%) \text {-silenced cells in control }(\%)}{\text { fluorescing cells in control }(\%)} \times 100
$$

GE (\%): gene silencing efficiency in percent.

HeLa-eGFP cells cultivated under the same conditions but without any treatment were used as control.

\section{Results and discussion}

The size and surface charge of a drug carrier are crucial parameters for its ability to cross the cellular membrane by endocytosis. ${ }^{42-44}$ Thus, the aim of this study was to synthesize a carrier system in the size range below $300 \mathrm{~nm}$ with high encapsulation efficiencies for hydrophilic biologicals. With the classical $\mathrm{W}_{1} / \mathrm{O} / \mathrm{W}_{2}$-emulsion solvent evaporation technique, anionic low molecular weight compounds (e.g., siRNA) easily escape from the inner aqueous phase $\left(\mathrm{W}_{1}\right)$ into the outer water phase $\left(\mathrm{W}_{2}\right)$ due to their hydrophilicity, low molecular weight, and to the electrostatic repulsion of the phosphate backbone and the carboxylic acid end groups of the polymer. ${ }^{18}$ Therefore, we modified the classical $\mathrm{W}_{1} / \mathrm{O} / \mathrm{W}_{2}$-emulsion solvent evaporation technique and took advantage of the high adsorption capacity of calcium phosphate nanoparticles for anionic, hydrophilic compounds and encapsulated the biomolecule functionalized calcium phosphate nanoparticles into the polymeric PLGA matrix (Fig. 2).

First of all, calcium phosphate nanoparticles were synthesized with a rapid precipitation method. As indicated by our previous work, the nucleic acids adsorb on the surface of the calcium phosphate nanoparticles. Hence, crystal growth is inhibited and the calcium phosphate nanoparticles are electrostatically stabilized. In this case, DNA or siRNA act both as pharmaceutical active ingredient and as stabilizing agent that protects the dispersion from aggregation. 
To protect the outer shell of DNA or siRNA from degrading enzymes like DNases or RNases and to provide a sustained release profile to the particles, the calcium phosphate-DNA or calcium phosphate-siRNA nanoparticles were then encapsulated into a matrix of PLGA (Fig. 2). The aqueous calcium phosphate-DNA or calcium phosphate-siRNA dispersion was used as the inner aqueous phase $\left(\mathrm{W}_{1}\right)$ in the emulsion process. The polymer was dissolved in dichloromethane (O). Sonication led to the primary $\mathrm{W}_{1} / \mathrm{O}$ emulsion with fine water droplets (containing the calcium phosphate nanoparticles) in the oil phase. Addition to the continuous water phase (PVA in water) and subsequent sonication led to a stable $\mathrm{W}_{1} / \mathrm{O} / \mathrm{W}_{2}$-emulsion. Evaporation of the organic solvent under reduced pressure yielded an almost transparent dispersion. The resulting nanoparticles could be freeze-dried without the addition of any cryoprotectant. This is a major advantage compared to previously reported calcium phosphate nanoparticles, which lack of a good storability without the addition of high amounts of cryoprotectants. $^{36,38,41,45-49}$

For the functionalization with biomolecules that adsorb to calcium phosphate nanoparticles but do not colloidally stabilize them (e.g., proteins like FITC-BSA), calcium phosphate was precipitated during the emulsion process in the primary $\mathrm{W}_{1} / \mathrm{O}$-emulsion (Fig. 3 ).

According to Landfester et al., it is possible to precipitate inorganic salts in the inner aqueous droplets of the primary emulsion. ${ }^{50,51}$ Thus, we prepared two $\mathrm{W}_{1} / \mathrm{O}$-emulsions in the first step (Fig. 3). Emulsion A contained the phosphate salt solution, and the biomolecules in the inner water droplets and PLGA were dissolved in the organic phase. Emulsion B contained the calcium salt solution in the inner aqueous phase and also PLGA dissolved in the organic phase. Mixing both emulsions under sonication led to the precipitation of calcium phosphate in the inner water droplets. Addition of the combined $\mathrm{W}_{1} / \mathrm{O}$-emulsions into the continuous water phase (PVA in water) and sonication led to a stable $\mathrm{W}_{1} / \mathrm{O} / \mathrm{W}_{2}$-emulsion. Evaporation of the organic solvent under reduced pressure gave an almost transparent, yellow dispersion. With this method, crystal growth was limited by the small volume of the water droplet serving as a microreactor in the organic solvent. We believe that BSA acts as a surfactant stabilizing the primary $\mathrm{W}_{1}$ /O-emulsion and thus defining the volume of the microreactors. Without the addition of BSA, large aggregates of calcium phosphate precipitated during the emulsion process. Dynamic light scattering showed particles with an average size of $190 \mathrm{~nm}$ and a zeta potential of $-24 \mathrm{mV}$. Scanning electron micrographs showed spherical particles with an average size of $105 \pm 18 \mathrm{~nm}$ (Fig. 4A and C). Dynamic light scattering of the nucleic acid-loaded PLGA nanoparticles showed a dispersion with an average particle size of $200 \mathrm{~nm}$ and a zeta potential of $-24 \mathrm{mV}$ (Fig. 4B and D). The calcium phosphate-PLGA nanoparticles contained 5\% calcium phosphate as determined by atomic absorption spectroscopy (computed from the content of calcium and assuming the stoichiometry of hydroxyapatite; $\left.\mathrm{Ca}_{5}\left(\mathrm{PO}_{4}\right)_{3} \mathrm{OH}\right)$.

To enhance the cellular uptake of the calcium phosphatePLGA nanoparticles, the surface charge can be reversed by layer- by-layer deposition of cationic polymers like chitosan or PEI. Furthermore, these polymers are capable to induce the proton sponge effect. ${ }^{52}$ This leads to an enhanced endosomal escape of the nanoparticles and an increased therapeutic efficiency. As shown by zeta potential measurements, the surface charge of the calcium phosphate-PLGA nanoparticles was easily reversed by layer-by-layer deposition of chitosan from about $-24 \mathrm{mV}$ to +50 mV (chitosan) or to $+31 \mathrm{mV}$ (PEI) (Fig. 4D).

Especially for expensive biopharmaceutical ingredients like antibodies, siRNA or DNA, the encapsulation efficiency of a drug carrier is an important factor in galenics. By the addition of calcium phosphate nanoparticles during the emulsion process, the encapsulation efficiency of the hydrophobic polymer PLGA could be optimized to $37 \%$ for siRNA, $52 \%$ for pDNA and $78 \%$ for FITC-BSA (Fig. 5) with total loadings of $8 \mu \mathrm{g}$ siRNA, $5 \mu \mathrm{g}$ pDNA and $280 \mu \mathrm{g}$ FITC-BSA per $\mathrm{mg}$ of PLGA nanoparticles. These total loadings correspond to 1880 molecules FITC-BSA, 250 molecules siRNA, and 0.6 molecules pDNA per nanoparticle. Although these numbers seem to be low, especially for nucleic acids, the total loadings are high compared to previously reported PLGA nanoparticles with total loadings of $0.7 \mu \mathrm{g}$ to $10 \mu \mathrm{g}$ per mg of PLGA nanoparticles. ${ }^{\mathbf{1 0 , 1 8}}$

The number of nanoparticles were calculated by taking the concentration of calcium phosphate-PLGA nanoparticles in the dispersion and assuming spherical nanoparticles with a diameter of $100 \mathrm{~nm}$ (eqn (3)). The number of biomolecules in the dispersion and per nanoparticle was determined by eqn (4) and (5), respectively.

$$
\begin{aligned}
N(\mathrm{NP}) & =\frac{m(\mathrm{CaP}-\mathrm{PLGA})}{m(\mathrm{NP})} \\
& =\frac{3 m(\mathrm{CaP}-\mathrm{PLGA})}{4 \pi r(\mathrm{NP})^{3} \rho(0.05 \rho(\mathrm{CaP})+0.95 \rho(\mathrm{PLGA}))}
\end{aligned}
$$

with $N(\mathrm{NP})$ : number of nanoparticles per $\mathrm{m}^{3}$; $m$ (CaP-PLGA): mass of synthesized calcium phosphate-PLGA nanoparticles per $\mathrm{m}^{3}$ with $m($ CaP-PLGA $)=1.0 \mathrm{~kg} \mathrm{~m}^{-3}, m(\mathrm{NP})$ mass of one calcium phosphate-PLGA nanoparticle: $m(\mathrm{NP})=7.5 \times 10^{-19} \mathrm{~kg} ; r(\mathrm{NP})$ average radius of one nanoparticle: $r(\mathrm{NP})=50 \times 10^{-9} \mathrm{~m}$; $\rho(\mathrm{CaP})$ : density of calcium phosphate as hydroxyapatite $=3140$ $\mathrm{kg} \mathrm{m}^{-3} ; \rho(\mathrm{PLGA})$ : density of PLGA $=1.340 \mathrm{~kg} \mathrm{~m}^{-3}$.

$$
N(\text { biomolecule })=c(\text { biomolecule }) \times N_{\mathrm{A}}
$$

with $N$ (biomolecule): number of biomolecules per $\mathrm{m}^{3}$; $c$ (biomolecule): concentration of the biomolecule in the nanoparticle dispersion; $N_{\mathrm{A}}$ : Avogadro constant: $N_{\mathrm{A}}=6.022 \times 10^{23} \mathrm{~mol}^{-1}$.

$N($ biomolecule $/ \mathrm{NP})=\frac{\text { Number of biomolecules in dispersion }}{\text { Number of nanoparticles in dispersion }}$

Incubation of HeLa cells expressing the lysosomal marker protein Lamp1-RFP with calcium phosphate-FITC-BSA-PLGA nanoparticles and co-localisation analyses demonstrated that the nanoparticles were efficiently taken up by the cells. As shown in Fig. 6, nanoparticles with a negative surface charge had a low affinity to the cell membrane and were taken up 


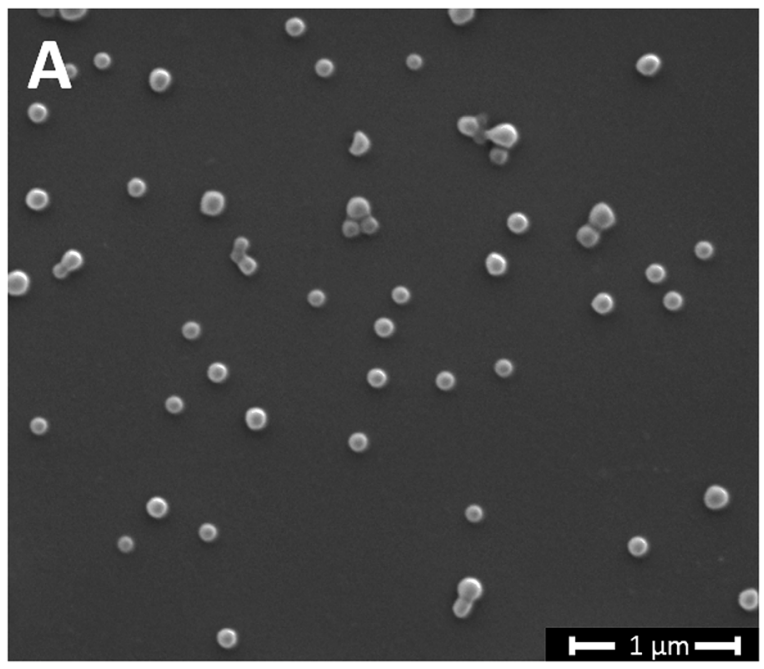

B
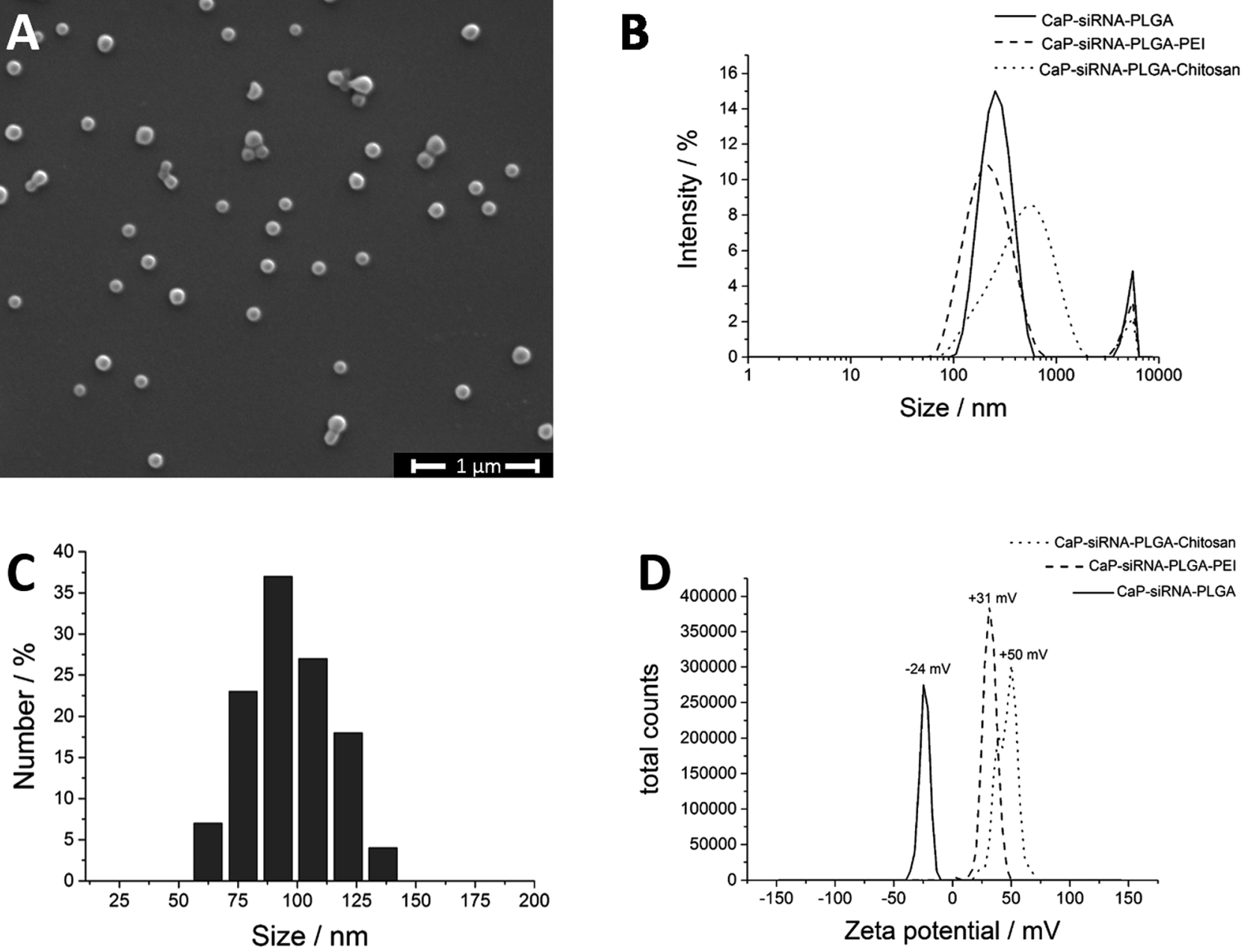

Fig. 4 Scanning electron micrograph and particle size distribution of FITC-BSA-loaded PLGA nanoparticles. The average diameter of the spherical particles was $105 \pm 18 \mathrm{~nm}$ (A, C). Dynamic light scattering data of anionic and cationic calcium phosphate/nucleic acid/PLGA nanoparticles (B, D).

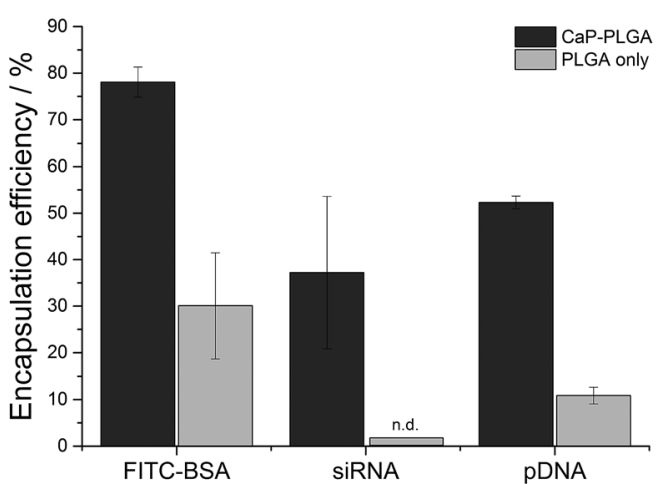

Fig. 5 Comparison of the encapsulation efficiency of FITC-BSA, siRNA, and pDNA into PLGA nanoparticles with (black) and without (grey) the addition of calcium phosphate nanoparticles. Without the addition of calcium phosphate, siRNA was not detectable (n.d.) inside the PLGA nanoparticles. Values are given as the mean \pm SD of triplicates. ${ }^{*}$ indicates $p<0.05$. only moderately, while nanoparticles with a positive surface charge (chitosan- or PEI-functionalized nanoparticles) covered the cell membrane after $1 \mathrm{~h}$ of incubation due to electrostatic interactions of the negatively charged cell membrane and the cationic surface of the nanoparticles. In addition, the majority of the negatively charged calcium phosphate-FITC-BSA-PLGA nanoparticles ended up in the endo-/lysosome as shown by the co-localisation of Lamp1-RFP and the green fluorescence of FITC-BSA (yellow fluorescence by overlay of green and red). In contrast, chitosan- and PEIfunctionalized calcium phosphate-FITC-BSA-PLGA nanoparticles (positive surface charge) induced the proton sponge effect and escaped the endosome as shown by the diffuse green fluorescence in the cytosol after $3 \mathrm{~h}$ of incubation (no co-localisation with Lamp1-RFP).

Calcium phosphate-PLGA nanoparticles loaded with eGFPencoding plasmid DNA (eGFP-DNA) showed only a moderate transfection efficiency in HeLa cells $(8 \pm 2 \%)$. However, in comparison to the liposomal transfection agent Lipofectamine 2000 which showed a transfection efficiency of $57 \%$, the 

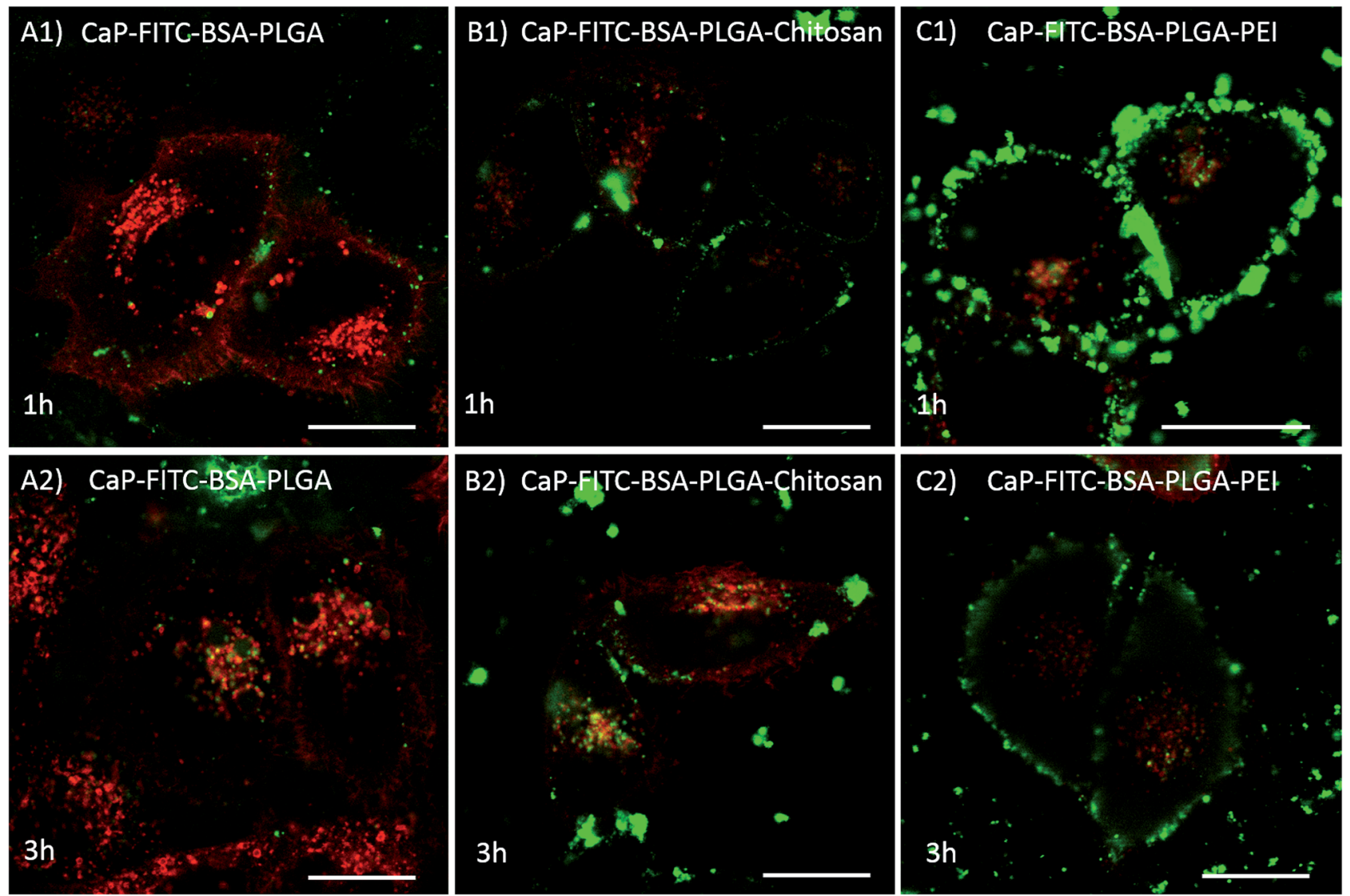

Fig. 6 Confocal laser scanning microscopic images of HeLa cells (life cell imaging) $1 \mathrm{~h}(\mathrm{~A} 1-\mathrm{C} 1)$ and $3 \mathrm{~h}$ (A2-C2) after incubation with anionic calcium phosphate-FITC-BSA-PLGA nanoparticles (A1 and A2), cationic calcium phosphate-FITC-BSA-PLGA-chitosan nanoparticles (B1 and B2), and cationic calcium phosphate-FITC-BSA-PLGA-PEI nanoparticles (C1 and C2). The particles showed a green fluorescence in all cases, and the lysosomes were stained red by transfection of Lamp1-RFP. Note that due to the life cell imaging experiment, there are many fluorescing particles in the dispersion, unlike as in post-hoc experiments with fixed and washed cells. The scale bar corresponds to $20 \mu \mathrm{m}$.

viability of the cells after the transfection was very high (85 $\pm 4 \%$ in comparison to $26 \pm 14 \%$, Fig. 7$).^{23}$

Calcium phosphate-PLGA nanoparticles functionalized with eGFP-siRNA efficiently silenced the eGFP-expression in eGFPexpressing HeLa cells. Anionic calcium phosphate-PLGA nanoparticles showed a knockdown efficiency of $53 \%$, which is comparable to anionic triple shell nanoparticles (calcium phosphate/siRNA/calcium phosphate/siRNA) or anionic calcium phosphate/siRNA nanoparticles coated with a conjugate of 3,4-dihydroxy-L-phenylalanine (dopa) and hyaluronic acid described earlier. ${ }^{38,53}$ The cationic calcium phosphatePLGA-siRNA nanoparticles coated with either chitosan or PEI showed knockdown efficiencies of $68 \%$ and $89 \%$, respectively (Fig. 8 and 9). In accordance to the transfection experiments, the vitality of the cells after the treatment with calcium phosphate-PLGA nanoparticles was twice as high in comparison to liposomal transfection agents such as Lipofectamine. The cationic calcium phosphate-PLGA-siRNA nanoparticles coated with either chitosan or PEI showed only moderate cytotoxic effects, although PEI is known for its high cytotoxicity. ${ }^{\mathbf{2 1 , 5 4}}$

We have tried to determine the release rate of a labelled oligonucleotide from calcium phosphate-PLGA nanoparticles by UV spectroscopy. However, this turned out to be impossible.

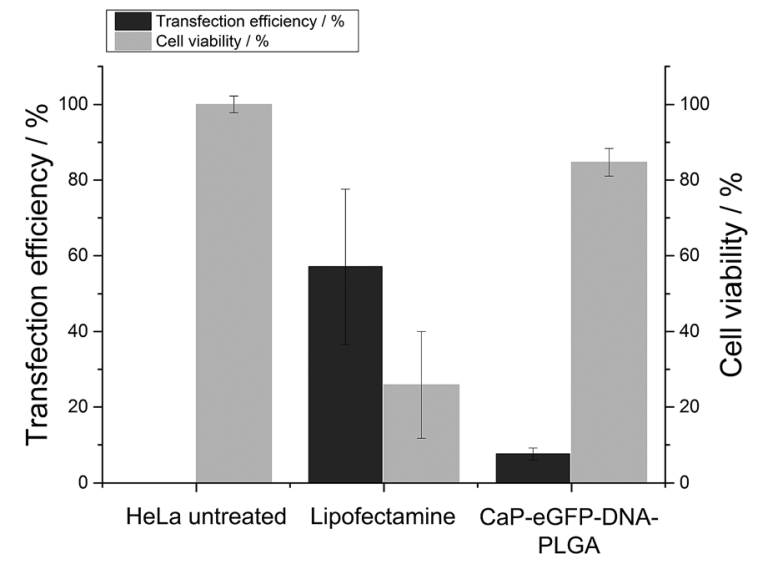

Fig. 7 Transfection efficiency and viability of HeLa cells after the treatment with calcium phosphate-eGFP-DNA-PLGA nanoparticles in comparison to Lipofectamine.

At the physiological pH 7.4 at $37{ }^{\circ} \mathrm{C}$, there was no release of the oligonucleotide during one week, probably because the degradation of PLGA was very slow and the diffusion of the oligonucleotide was prevented. The calcium phosphate 

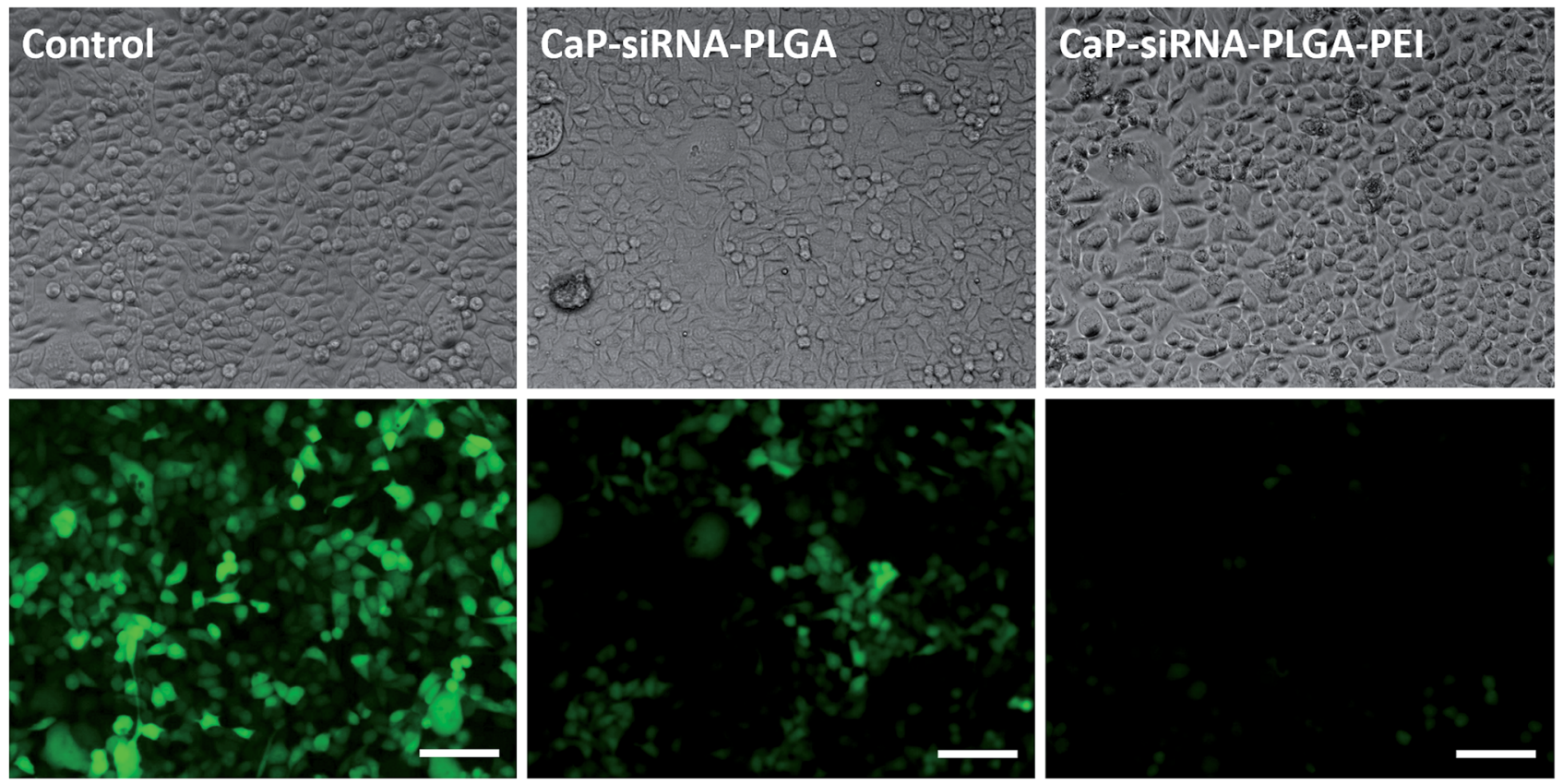

Fig. 8 Light and fluorescence microscopic images of eGFP-expressing HeLa cells as control, calcium phosphate-siRNA-PLGA nanoparticles, and calcium phosphate-siRNA-PLGA-PEI nanoparticles. The scale bar corresponds to $100 \mu \mathrm{m}$.

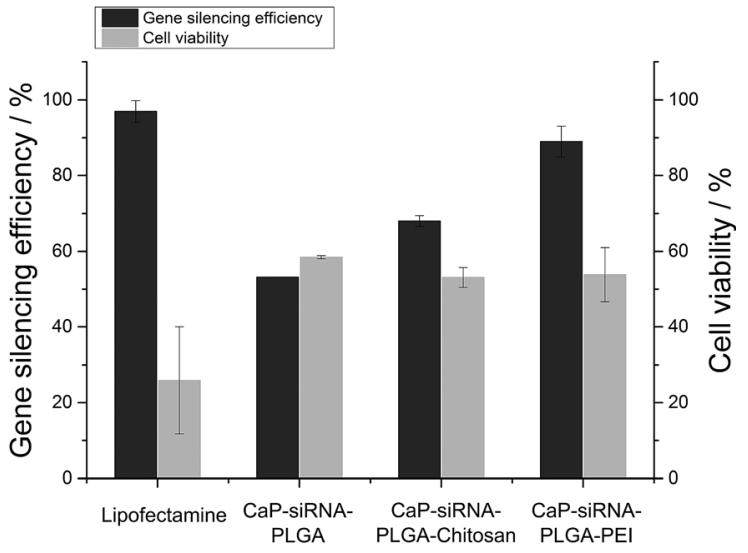

Fig. 9 Gene silencing efficiency and cell viability of eGFP-expressing HeLa cells after the treatment with calcium phosphate-siRNA-PLGA nanoparticles, calcium phosphate-siRNA-PLGA-chitosan nanoparticles, and calcium phosphate-siRNA-PLGA-PEI nanoparticles in comparison to Lipofectamine.

nanoparticles also do not dissolve at a $\mathrm{pH}$ 7.4. This is advantageous for a later in vivo drug release application because the drug does not leach out of the nanoparticles during circulation.

After crossing the cell membrane, the particles will end up first in an endosome and then in a lysosome at a $\mathrm{pH}$ around $4 .^{31,55}$ Therefore, the delivery will occur after dissolution of the nanoparticle at a low $\mathrm{pH}$. In this case, calcium phosphate will dissolve and PLGA will slowly degraded by acid, but also by nucleases. ${ }^{9}$

Under the given precipitation conditions, calcium phosphate nanoparticles are spherical with a diameter of about 50-100 nm. They are typically X-ray amorphous but show domains of hydroxyapatite in the transmission electron microscope, with indications for carbonate inclusion. ${ }^{56}$ As they are prepared around neutral $\mathrm{pH}$, they probably consist of calcium-deficient hydroxyapatite (CDHA). ${ }^{24,57}$ In the case of nanoparticles, the dissolution rate at a $\mathrm{pH}$ of 4 as encountered in the lysosome should not be significantly affected by the stoichiometry. ${ }^{\mathbf{5 8 , 5 9}}$

The lysosomal degradation was impossible to replicate in this case. The immersion of the calcium phosphate-PLGA nanoparticles in buffer at $\mathrm{pH} 4$ led to agglomeration because the colloidal stability was lost and the particles agglomerated. This will not occur in the lysosome, as the particles will be taken up individually, but it constrains the experimental release study. However, the fact that we observe a successful transfection and gene silencing proves that the nucleic acids are released into the cytoplasm after cellular uptake without harmful degradation.

\section{Conclusions}

We have shown that the encapsulation efficiency of hydrophilic and anionic biomolecules such as siRNA, plasmid DNA, and FITC-BSA into PLGA nanoparticles can be strongly increased by the addition of calcium phosphate nanoparticles into the inner aqueous phase $\left(\mathrm{W}_{1}\right)$ during a classic $\mathrm{W}_{1} / \mathrm{O} / \mathrm{W}_{2}$ emulsion solvent evaporation synthesis. DNA or siRNA interact with the surface of the calcium phosphate nanoparticles and act both as pharmaceutical active ingredient and as a stabilizing agent. The additional PLGA matrix protects the outer shell of DNA or siRNA from degrading enzymes like nucleases and proteases and provides the particles with a good storability in freeze-dried form, without the necessity of a cryoprotectant. A special challenge during this synthesis route was to obtain nanoparticles with a diameter below $200 \mathrm{~nm}$. Therefore, it was necessary to 
add acetylated BSA into the inner aqueous phase $\left(\mathrm{W}_{1}\right)$ to stabilize the primary $\mathrm{W}_{1} / \mathrm{O}$ emulsion. To enhance the cellular uptake of anionic calcium phosphate-PLGA nanoparticles, the surface of these particles was coated with cationic polymers such as chitosan and PEI.

As shown by confocal laser scanning microscopy and coexpression of the endosomal marker protein Lamp1-RFP, the nanoparticles are very efficiently taken up by endocytosis. Chitosan- and PEI-coated nanoparticles have a strong affinity to the anionic cellular membrane, induce the proton sponge effect and escape the endosome. In addition, transfection and gene silencing experiments showed that sensitive biomolecules like siRNA and DNA can be encapsulated inside PLGA nanoparticles by the addition of calcium phosphate, and efficiently delivered across the cell membrane. Furthermore, the cytotoxicity of calcium phosphatePLGA nanoparticles is low in comparison to liposomal transfection agents. Thus, calcium phosphate-PLGA nanoparticles represent a very promising delivery system for hydrophilic anionic drugs, e.g. for nucleic acids in gene therapy, because of their good biocompatibility and high encapsulation efficiency.

\section{Acknowledgements}

This work was supported by Evonik Industries, Darmstadt and by the Deutsche Forschungsgemeinschaft (DFG) in the framework of the Collaborative Research Center "Supramolecular Chemistry on Proteins" (SFB 1093).We thank Dr J. MuellerAlbers and Dr S. Grimm for helpful discussions.

\section{References}

1 G. L. Amidon, H. Lennernaes, V. P. Shah and J. R. Crison, Pharm. Res., 1995, 12, 413-420.

2 C. X. Li, A. Parker, E. Menocal, S. Xiang, L. Borodyansky and J. H. Fruehauf, Cell Cycle, 2006, 5, 2103-2109.

3 G. L. Verdine and L. D. Walensky, Clin. Cancer Res., 2007, 13, 7264-7270.

4 Z. P. Xu, Q. H. Zeng, G. Q. Lu and A. B. Yu, Chem. Eng. Sci., 2006, 61, 1027-1040.

5 J. Kurreck, Angew. Chem., Int. Ed., 2009, 48, 1378-1398.

6 V. Sokolova and M. Epple, Angew. Chem., Int. Ed., 2008, 47, 1382-1395.

7 V. Sokolova, O. Rotan, J. Klesing, P. Nalbant, J. Buer, T. Knuschke, A. M. Westendorf and M. Epple, J. Nanopart. Res., 2012, 14, 910.

8 O. Rotan, V. Sokolova, P. Gilles, W. Hu, S. Dutt, T. Schrader and M. Epple, Materialwiss. Werkstofftech., 2013, 44, 176-182.

9 B. D. Ulery, L. S. Nair and C. T. Laurencin, J. Polym. Sci., Part B: Polym. Phys., 2011, 49, 832-864.

10 F. Danhier, E. Ansorena, J. M. Silva, R. Coco, B. A. Le and V. Preat, J. Controlled Release, 2012, 161, 505-522.

11 A. Kumari, S. K. Yadav and S. C. Yadav, Colloids Surf., B, 2010, 75, 1-18.

12 J. Panyam and V. Labhasetwar, Adv. Drug Delivery Rev., 2003, 55, 329-347.

13 J. K. Vasir and V. Labhasetwar, Adv. Drug Delivery Rev., 2007, 59, 718-728.
14 A. Giteau, M. C. Venier-Julienne, A. Aubert-Pouessel and J. P. Benoit, Int. J. Pharm., 2008, 350, 14-26.

15 D. Luo, K. Woodrow-Mumford, N. Belcheva and W. M. Saltzman, Pharm. Res., 1999, 16, 1300-1308.

16 C. Perez, A. Sanchez, D. Putnam, D. Ting, R. Langer and M. J. Alonso, J. Controlled Release, 2001, 75, 211-224.

17 K. A. Woodrow, Y. Cu, C. J. Booth, J. K. Saucier-Sawyer, M. J. Wood and W. M. Saltzman, Nat. Mater., 2009, 8, 526533.

18 D. Cun, D. K. Jensen, M. J. Maltesen, M. Bunker, P. Whiteside, D. Scurr, C. Foged and H. M. Nielsen, Eur. J. Pharm. Biopharm., 2011, 77, 26-35.

19 C. G. Oster, N. Kim, L. Grode, L. Barbu-Tudoran, A. K. Schaper, S. H. E. Kaufmann and T. Kissel, J. Controlled Release, 2005, 104, 359-377.

20 Y. C. Tseng, Z. Xu, K. Guley, H. Yuan and L. Huang, Biomaterials, 2014, 35, 4688-4698.

21 C. Brunot, L. Ponsonnet, C. Lagneau, P. Farge, C. Picart and B. Grosgogeat, Biomaterials, 2007, 28, 632-640.

22 W. T. Godbey, M. A. Barry, P. Saggau, K. K. Wu and A. G. Mikos, J. Biomed. Mater. Res., 2000, 51, 321-328.

23 H. T. Lv, S. B. Zhang, B. Wang, S. H. Cui and J. Yan, J. Controlled Release, 2006, 114, 100-109.

24 S. V. Dorozhkin and M. Epple, Angew. Chem., Int. Ed., 2002, 41, 3130-3146.

25 L. Treccani, T. Y. Klein, F. Meder, K. Pardun and K. Rezwan, Acta Biomater., 2013, 9, 7115-7150.

26 V. Uskokovic and D. P. Uskokovic, J. Biomed. Mater. Res., Part $B, 2011,96,152-191$.

27 M. Epple, K. Ganesan, R. Heumann, J. Klesing, A. Kovtun, S. Neumann and V. Sokolova, J. Mater. Chem., 2010, 20, 18-23.

28 Y. Cai and R. Tang, J. Mater. Chem., 2008, 18, 3775-3787.

29 A. E. Ewence, M. Bootman, H. L. Roderick, J. N. Skepper, G. McCarthy, M. Epple, M. Neumann, C. M. Shanahan and D. Proudfoot, Circ. Res., 2008, 103, e28-e32.

30 S. Neumann, A. Kovtun, I. D. Dietzel, M. Epple and R. Heumann, Biomaterials, 2009, 30, 6794-6802.

31 V. Sokolova, D. Kozlova, T. Knuschke, J. Buer, A. M. Westendorf and M. Epple, Acta Biomater., 2013, 9, 7527-7535.

32 D. Zhao, C. Q. Wang, R. X. Zhuo and S. X. Cheng, Colloids Surf., B, 2014, 118, 111-116.

33 V. Uskokovic, C. Hoover, M. Vukomanovic, D. P. Uskokovic and T. A. Desai, Mater. Sci. Eng., C, 2013, 33, 3362-3373.

34 N. L. Ignjatovic, P. Ninkov, R. Sabetrasekh and D. P. Uskokovic, J. Mater. Sci.: Mater. Med., 2010, 21, 231239.

35 N. L. Ignjatovic, C. Z. Liu, J. T. Czernuszka and D. P. Uskokovic, Acta Biomater., 2007, 3, 927-935.

36 J. Klesing, S. Chernousova and M. Epple, J. Mater. Chem., 2012, 22, 199-204.

37 V. Sokolova, Synthesis, characterization and application of calcium phosphate nanoparticles for the transfection of cells, PhD Thesis, University of Duisburg-Essen, Germany, 2006. 
38 V. Sokolova, A. Kovtun, O. Prymak, W. Meyer-Zaika, E. A. Kubareva, E. A. Romanova, T. S. Oretskaya, R. Heumann and M. Epple, J. Mater. Chem., 2007, 17, 721727.

39 J. Tang, J. Y. Chen, J. Liu, M. Luo, Y. J. Wang, X. W. Wei, X. Gao, B. L. Wang, Y. B. Liu, T. Yi, A. P. Tong, X. R. Song, Y. M. Xie, Y. Zhao, M. Xiang, Y. Huang and Y. Zheng, Int. J. Pharm., 2012, 431, 210-221.

40 S. Tenzer, D. Docter, J. Kuharev, A. Musyanovych, V. Fetz, R. Hecht, F. Schlenk, D. Fischer, K. Kiouptsi, C. Reinhardt, K. Landfester, H. Schild, M. Maskos, S. K. Knauer and R. H. Stauber, Nat. Nanotechnol., 2013, 8, 772-781.

41 V. V. Sokolova, I. Radtke, R. Heumann and M. Epple, Biomaterials, 2006, 27, 3147-3153.

42 I. Canton and G. Battaglia, Chem. Soc. Rev., 2012, 41, 27182739.

43 T. G. Iversen, T. Skotland and K. Sandvig, Nano Today, 2011, 6, 176-185.

44 G. Sahay, D. Y. Alakhova and A. V. Kabanov, J. Controlled Release, 2010, 145, 182-195.

45 V. Sokolova, S. Neumann, A. Kovtun, S. Chernousova, R. Heumann and M. Epple, J. Mater. Sci., 2010, 45, 49524957.

46 Y. Xie, H. Qiao, Z. Su, M. Chen, Q. Ping and M. Sun, Biomaterials, 2014, 35, 7978-7991.

47 J. Wang, B. Chen, D. Zhao, Y. Peng, R. X. Zhuo and S. X. Cheng, Int. J. Pharm., 2013, 446, 205-210.

48 K. Lee, M. H. Oh, M. S. Lee, Y. S. Nam, T. G. Park and J. H. Jeong, Int. J. Pharm., 2013, 445, 196-202.
49 T. Ito, Y. Koyama and M. Otsuka, J. Pharm. Sci., 2014, 103, 179-184.

50 A. Hamberger, U. Ziener and K. Landfester, Macromol. Chem. Phys., 2013, 214, 691-699.

51 N. Nabih, K. Landfester and A. Taden, J. Polym. Sci., Part A: Polym. Chem., 2011, 49, 5019-5029.

52 O. Boussif, F. Lezoualch, M. A. Zanta, M. D. Mergny, D. Scherman, B. Demeneix and J. P. Behr, Proc. Calif. Acad. Sci., 1995, 92, 7297-7301.

53 M. S. Lee, J. E. Lee, E. Byun, N. W. Kim, K. Lee, H. Lee, S. J. Sim, D. S. Lee and J. H. Jeong, J. Controlled Release, 2014, 192, 122-130.

54 P. Dubruel, B. Christiaens, B. Vanloo, K. Bracke, M. Rosseneu, J. Vandekerckhove and E. Schacht, Eur. J. Pharm. Sci., 2003, 18, 211-220.

55 J. Dausend, A. Musyanovych, M. Dass, P. Walther, H. Schrezenmeier, K. Landfester and V. Mailänder, Macromol. Biosci., 2008, 8, 1135-1143.

56 H. Urch, M. Vallet-Regi, L. Ruiz, J. M. Gonzalez-Calbet and M. Epple, J. Mater. Chem., 2009, 19, 2166-2171.

57 R. Z. LeGeros, Calcium phosphates in oral biology and medicine, Karger, Basel, 1991.

58 D. Tang, L. Wang, C. A. Orme, T. Bonstein, P. J. Bush and G. H. Nancollas, Angew. Chem., 2004, 116, 2751-2755.

59 R. Detsch, D. Hagmeyer, M. Neumann, S. Schaefer, A. Vortkamp, M. Wuelling, G. Ziegler and M. Epple, Acta Biomater., 2010, 6, 3223-3233. 